\title{
Association of individual aortic leaflet calcification on paravalvular regurgitation and conduction abnormalities with self-expanding trans-catheter aortic valve insertion
}

\author{
Ciara Mahon ${ }^{1}$, Allan Davies ${ }^{1}$, Alessia Gambaro ${ }^{1}$, Francesca Musella ${ }^{1}$, Ana Luisa Costa ${ }^{1}$, \\ Vasileios Panoulas ${ }^{1}$, Edward Nicol ${ }^{1,2}$, Alison Duncan ${ }^{1}$, Simon Davies ${ }^{1}$, Saeed Mirsadraee ${ }^{1}$ \\ ${ }^{1}$ Royal Brompton and Harefield NHS Foundation Trust, London, UK; ${ }^{2}$ National Heart and Lung Institute, Imperial College London, London, UK \\ Correspondence to: Dr. Ciara Mahon. Royal Brompton and Harefield NHS Foundation Trust, Sydney Street, London, SW3 6NP, UK. \\ Email: c.mahon@rbht.nhs.uk.
}

\begin{abstract}
Background: Complication rates of paravalvular aortic regurgitation (PVR) and permanent pacemaker insertion remain high in patients undergoing trans-catheter aortic valve insertion for severe aortic stenosis. The spatial distribution of calcium between individual aortic valve leaflets, and its potential role in these complications is gaining interest. We aimed to assess the accuracy of individual aortic valve leaflet calcium quantification, and to determine its effect on the frequency of these complications.

Methods: This was a retrospective study of 251 patients who underwent trans-catheter aortic valve insertion using the Evolut RTM valve. The off-line Terarecon software platform was used for Agatston scoring the short axis views.

Results: There was a correlation between the sum of the individual leaflet and the total aortic valve calcium score. There was a univariate association between an increase [per 100 Agatston unit (AU)] in both right coronary leaflet (RCL) and left coronary leaflet (LCL) calcium with the risk of PVR. There was an association between an increase in LCL calcium score (per $100 \mathrm{AU}$ ) and need for post-implantation balloon aortic valvuloplasty (BAV). There was no association between individual leaflet calcification on the risk of permanent pacemaker insertion.

Conclusions: This study supports the idea that a quantifiable and reproducible method of individual valve leaflet calcification score may serve as an independent risk factor for paravalvular regurgitation, beyond visual assessment of asymmetry. However, the same may not be true of spatial calcium distribution and permanent pacemaker implantation (PPI).
\end{abstract}

Keywords: Trans-catheter aortic valve implantation (TAVI); paravalvular aortic regurgitation (PVR); permanent pacemaker insertion

Submitted Oct 06, 2020. Accepted for publication Dec 29, 2020.

doi: $10.21037 /$ qims-20-1122

View this article at: http://dx.doi.org/10.21037/qims-20-1122

\section{Introduction}

Trans-catheter aortic valve implantation (TAVI) is a wellestablished therapeutic option for patients with severe calcific aortic stenosis. Acute and medium-term results are encouraging (1-6), but potential limitations include higher rates of paravalvular aortic regurgitation (PVR) (7-11) and permanent pacemaker implantation (PPI) (12) compared to surgical prostheses. This may impact on longer term outcomes. Acutely, severe PVR is poorly tolerated and can be associated with cardiac failure, longer recovery time and increased in-hospital mortality $(10,13,14)$, with mild to moderate PVR leading to less favourable clinical outcomes (15). PPI rates post TAVI are higher compared 
to surgical aortic valve replacement and range from $5-25 \%$ depending on the type of valve implanted (12). PPI increases the duration of hospitalisation, the rate of rehospitalisation and other potential complications (12).

There is increasing interest not only in quantifying total aortic valve calcification, but also the spatial distribution of aortic leaflet calcification and the effects of specific calcific distribution on clinical outcomes following TAVI. The severity of calcification of the non-coronary leaflet (NCL) was associated with significant PVR immediately after TAVI using the first generation self-expanding Medtronic Corevalve $^{\mathrm{TM}}$ (Medtronic Inc., Minneapolis, MN, USA) (16). NCL calcification is also an independent predictor of PPI post TAVI using the balloon expandable SAPIEN $3^{\text {TM }}$ valve (Edwards Lifesciences, Irvine, CA, USA) (17) The aim of this study was to further add to this knowledge base by assessing the feasibility of measuring the spatial distribution of aortic valve leaflet calcification in a large cohort of patients undergoing TAVI using the Medtronic Evolut $\mathrm{R}^{\mathrm{TM}}$ valve system, and to analyse the impact on the frequency and severity of PVR and PPI.

\section{Methods}

\section{Patient population and TAVI procedure}

This was a retrospective observational single centre study. Consecutive patients who had undergone TAVI with the self-expandable Medtronic Evolut $\mathrm{R}^{\mathrm{TM}}$ valve between January 2014 and November 2017 were eligible for inclusion. We chose these dates as it marked the beginning of the centre's experience with the Evolut $\mathrm{R}^{\mathrm{TM}}$, after transitioning from original CoreValve $\mathrm{T}^{\mathrm{TM}}$, and before transitioning again to the Evolut Pro $^{\mathrm{TM}}$. Exclusion criteria included patients undergoing TAVI using other valve systems (either balloon or self-expandable), patients undergoing "valve-in-valve" TAVI, bicuspid aortic valves, or where the indication was for aortic regurgitation. Patients with a pre-existing pacemaker were excluded from analysis of pacing outcomes and conduction changes on the electrocardiograph, but these patients were included for analysis of PVR. TAVI was performed using either sedation or general anaesthesia. Ethical approval was obtained from the institutional ethics board.

\section{Measurement of aortic valve calcification}

Multi-detector computer tomography (CT) assessment of the aortic valve was performed on a Siemens SOMATOM Definition Flash Dual Source scanner (Siemens Medical Solutions Inc., Forchheim, Germany). Patients underwent electrocardiogram (ECG) triggered non-contrast CT in diastole for the assessment of aortic valve calcium using a tube voltage of $80-120 \mathrm{kV}$, and the tube current was adjusted based on the body habitus. Images were reconstructed with filter back projection (512 matrix size, slice thickness of $3-\mathrm{mm}$ ). The aortic valve calcium score was measured on a dedicated workstation (Terarecon Intuition software, Terarecon Medical Imaging, Frankfurt, Germany), (Figure 1). Regions of interests were drawn around the aortic valve leaflet and annular calcification. Multiplanar re-orientation of the aortic root allows identification and measurement of the individual aortic valve leaflets, and to exclude non-leaflet calcification. Calcium in the coronary arteries, mitral valve annulus, left ventricular outflow tract (LVOT), and aortic sinus were excluded (18). Total calcium score was measured on axial images.

The analysis of the calcium score in each individual leaflet was performed on short axis reconstructions. The quantifications were performed by two experienced observers who were blinded to clinical and echocardiographic data and who were also blinded to the original aortic valve calcium score measurement made at the time of the clinical CT reporting.

A pilot cohort of 23 patients was used to assess interobserver variability in measurements of calcium scores within each leaflet. Assessment of agreement between the total calcium score, measured at the time of clinical CT reporting, and the sum of the scores of the individual leaflets was also undertaken.

\section{Study end-points}

\section{Paravalvular aortic regurgitation}

Peri-procedural PVR was assessed using angiography with a pigtail catheter placed in the ascending aorta. PVR was then formally assessed with transthoracic echocardiography prior to discharge and typically within 3 days after implantation. Assessment of the aortic valve was made using a combination of parasternal long-axis views, apical 5 chamber and apical 3 chamber views using conventional criteria. PVR was classified as mild, moderate or severe. We defined significant PVR as moderate or greater PVR on a pre-discharge echocardiogram. A secondary endpoint was the need for immediate balloon aortic valvuloplasty (BAV), or a second TAVI because of significant PVR. 

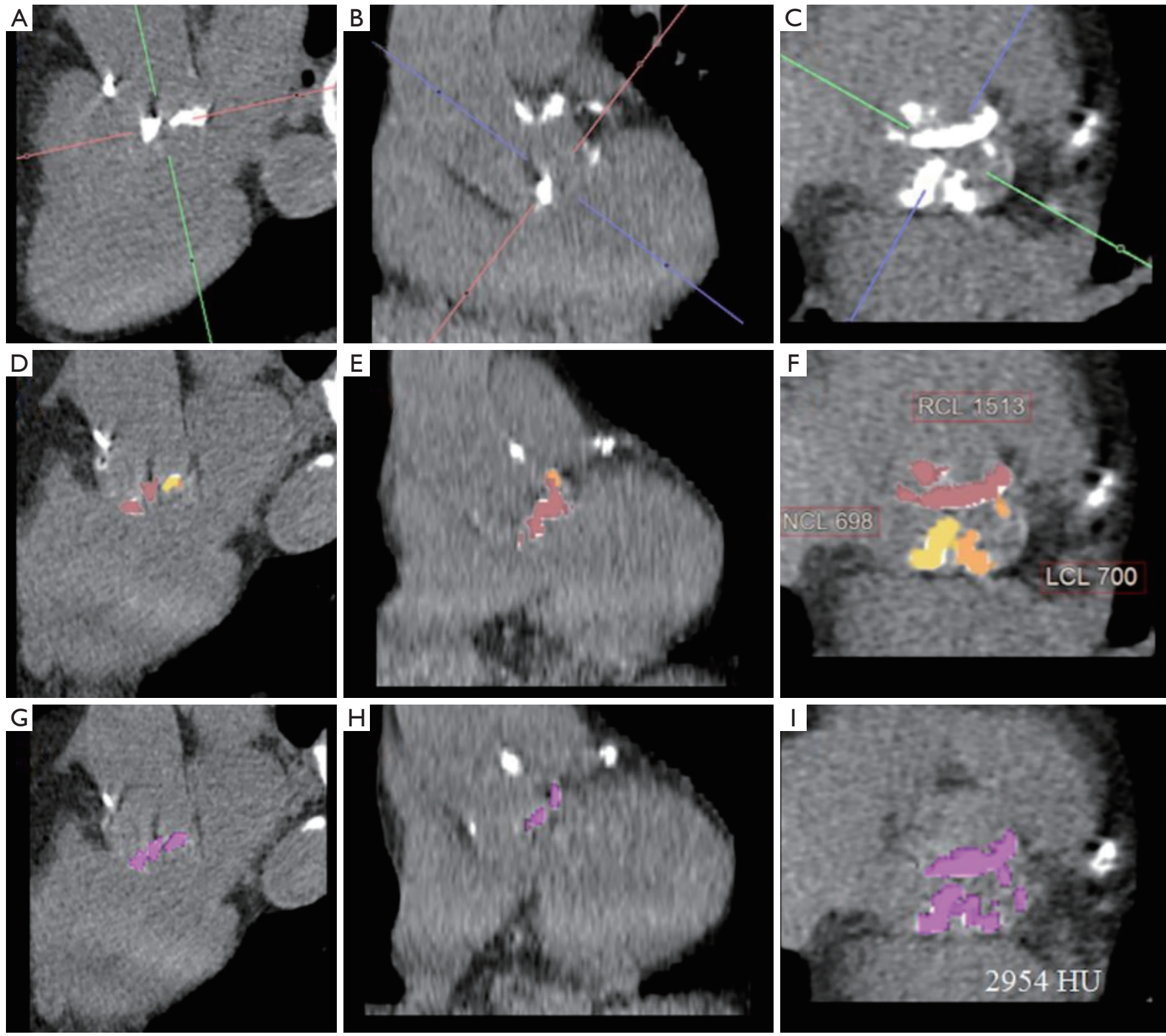

Figure 1 Aortic valve and individual aortic valve leaflet calcification assessment. (A-C) Multi-planar re-orientation of the aortic root allowing alignment to delineate the individual aortic leaflets and to avoid ascending aorta or other calcium; (D-F) demonstrates the measurement of individual aortic leaflet calcium in the absence of ascending aorta calcium; (G-I) demonstrates the measurement of total aortic (2,954 AU) in the absence of ascending aorta calcium. LCL, left coronary leaflet; NCL, non-coronary leaflet; RCL, right coronary leaflet; AU, Agatston unit.

\section{Permanent pacemaker insertion and conduction} abnormalities

All patients without a pre-existing permanent pacemaker were assessed immediately post implantation for significant conduction abnormalities and the decision to proceed with PPI was at the discretion of the treating cardiologist, in consultation with an electrophysiologist. The patient's medical record was searched for the most recent 12-lead ECG before TAVI and for a 12-lead ECG performed post TAVI but prior to discharge. The PR interval and QRS duration were recorded as well as the presence of new onset bundle branch block (BBB). 


\section{Statistical analysis}

Continuous variables are displayed as mean and standard deviation, or median and interquartile range if not normally distributed. Categorical variables are displayed as count and percentage. Comparison between continuous variables was made using $t$-tests or Mann-Whitney $\mathrm{U}$ test depending on the normality of the data. Chi-square or Fisher exact tests were used to compare categorical variables. Assessment of agreement between the sum of the off-line measured aortic valve leaflet calcium score and the originally measured result was performed using $t$-tests, Spearman correlation coefficient and Bland-Altman plots. We performed univariate and multivariate logistic regression to analyse the effect of the aortic valve leaflet calcium score on the risk for PVR and PPI. Because of the limited number of events of PVR, we adjusted for trans-catheter heart valve under sizing (dichotomous variable defined based on the manufacturer's CT derived perimeter recommended size and the actual implanted size) and eccentricity index of $>0.25(1-\mathrm{dmin} / \mathrm{dmax})(19)$ in the multivariate analysis. All statistical analyses were performed using STATA version 14 (StataCorp, TX, USA).

\section{Results}

We identified 251 consecutive patients who had undergone TAVI using the Medtronic Evolut $\mathrm{R}^{\mathrm{TM}}$ between January 2014 and December 2017, baseline characteristics were obtained (Table 1).

\section{Assessment of aortic valve leaflet calcium scores}

We performed a pilot study with 23 patients to assess the inter-observer variability in the measurement of the aortic valve leaflet calcium. Two investigators independently measured the Agatston score in each aortic valve leaflet, blinded to the results of the other with a high degree of correlation between measurements with each leaflet measurement demonstrating correlation coefficients greater than 0.92 (Figure 2). Bland-Altman plots did not show any evidence of systematic bias.

The mean total sum of the scores was $3,661 \pm 1,995$ Agatston unit (AU) in males and 2,802 $\pm 1,516$ AU in females. The mean difference between the sum of the individual scores and the overall score was 23 [95\% confidence interval (CI): -17.22 to 76.77$]$. There was a high correlation (Spearman correlation coefficient $=0.96$ ) between the sum of the individual aortic valve leaflet calcium scores and the originally calculated total aortic valve calcium score (Figure 3). Bland-Altman plots (Figure 4) showed no visual evidence of systematic bias between the two scores.

In our study group, the NCL had the highest mean calcium score $(1,210 \pm 726 \mathrm{AU})$ and the right coronary leaflet (RCL) had the lowest calcium score $(953 \pm 644 \mathrm{AU})$. There was a statistically significant difference in calcium scores between the left coronary leaflet $(\mathrm{LCL})$ and RCL $(\mathrm{P}<0.001)$, the LCL and NCL $(\mathrm{P}=0.04)$, and the NCL and RCL $(\mathrm{P}<0.001)$ (Table 2).

\section{Paravalvular aortic regurgitation}

At the time of discharge, echocardiographic information was available for 241 patients. The majority of patients (217; 90\%) had mild or less PVR, and 24 patients $(10 \%)$ had moderate or greater PVR. A 100 AU increase in RCL calcium score was associated with increased risk of PVR on both univariate [odds ratio (OR): 1.08; 95\% CI: 1.02-1.13] and multivariate (OR: 1.07; 95\% CI: 1.01-1.13) analysis. The LCL calcium score was also associated with increased risk of PVR on univariate (OR: 1.06; 95\% CI: 1.01-1.11) and multivariate (OR: 1.05; 95\% CI: 1.00-1.10) (Table 3). No association was found between the NCL calcium score and risk of PVR.

\section{Association between aortic valve calcium score and need for post-implantation $B A V$}

There was a statistically significant association between an increase in the aortic valve calcium score (per $100 \mathrm{AU}$ increase) and need for post-implantation BAV on both univariate (OR: 1.02 ; $95 \% \mathrm{CI}: 1.01-1.034, \mathrm{P}=0.002$ ) and after adjustment for under sizing and patients with high eccentricity index (OR: 1.02; 95\% CI: 1.007-1.036). The association was strongest with increases in LCL calcium, and this was significant on both univariate and multivariate assessment (Table 4).

\section{Effect of AV calcium score on need for pacing and change in conduction}

Out of 251 patients, 24 patients had received a PPI prior to TAVI and were therefore excluded from analysis. Of the remaining 227 patients, 51 (22.5\%) underwent PPI after TAVI. There was no association identified between a $100 \mathrm{AU}$ increase in the total $\mathrm{AV}$ calcium score and risk 
Table 1 Baseline characteristics

\begin{tabular}{|c|c|}
\hline Variables & Total $(n=270)$ \\
\hline Age (years) & 83 [78-86] \\
\hline Male sex, n (\%) & $148(54.81)$ \\
\hline BMI & $26.9(23.5-30.3)$ \\
\hline \multicolumn{2}{|l|}{ Diabetes, n (\%) } \\
\hline Non insulin dependent & $40(14.81)$ \\
\hline Insulin dependent & $13(4.81)$ \\
\hline Dyslipidaemia, n (\%) & $155(37 . X X)$ \\
\hline Hypertension, n (\%) & $165(61.57)$ \\
\hline CVA or TIA, n (\%) & $22(8.15)$ \\
\hline Smoking history, n (\%) & $140(51.85)$ \\
\hline COPD, n (\%) & $33(12.22)$ \\
\hline Previous MI, n (\%) & $32(11.85)$ \\
\hline Peripheral vascular disease, $\mathrm{n}(\%)$ & $18(6.67)$ \\
\hline History of AF, n (\%) & $77(28.51)$ \\
\hline Previous CABG, n (\%) & $17(6.30)$ \\
\hline \multicolumn{2}{|l|}{ Medications, n (\%) } \\
\hline Aspirin & $142(53.18)$ \\
\hline Statins & $165(61.57)$ \\
\hline Beta blockers & 78 (28.89) \\
\hline ACE or ARB & $80(29.63)$ \\
\hline Aldosterone antagonists & $27(10.04)$ \\
\hline Digoxin & $16(5.99)$ \\
\hline Calcium channel blockers & $25(9.33)$ \\
\hline P2Y12 inhibitor & 98 (36.29) \\
\hline \multicolumn{2}{|l|}{ Echocardiogram } \\
\hline Peak AV gradient (mmHg) & $78.7 \pm 23.11$ \\
\hline LVEF (\%) & $54 \pm 11.6$ \\
\hline Aortic valve area $\left(\mathrm{cm}^{2}\right)$ & $0.70 \pm 0.18$ \\
\hline Moderate or greater MR ( $\mathrm{n}=261), \mathrm{n}(\%)$ & $17(6.51)$ \\
\hline \multicolumn{2}{|l|}{ Valve type, n (\%) } \\
\hline Corevalve & $17(6.30)$ \\
\hline Evolut R & $251(92.96)$ \\
\hline Evolut Pro & $2(0.74)$ \\
\hline
\end{tabular}

Table 1 (continued)
Table 1 (continued)

\begin{tabular}{lc}
\hline Variables & Total $(\mathrm{n}=270)$ \\
\hline Valve size, $\mathrm{n}(\%)$ & \\
$23 \mathrm{~mm}$ & $51(18.89)$ \\
$26 \mathrm{~mm}$ & $113(41.85)$ \\
$29 \mathrm{~mm}$ & $100(37.04)$ \\
$31 \mathrm{~mm}$ & $2(0.74)$ \\
$34 \mathrm{~mm}$ & $4(1.48)$ \\
\hline
\end{tabular}

Continuous variables with normal distributions are presented as mean (standard deviation); non-normal variables were reported as median (interquartile range). BMI, body mass index; CVA, cerebrovascular accident; TIA, transient ischemic attack; COPD, chronic obstructive pulmonary disease; MI, myocardial infarction; $A F$, atrial fibrillation; $C A B G$, coronary artery bypass grafting; ACE, angiotensin-converting enzyme; $\mathrm{ARB}$, angiotensin-receptor blocker; AV, aortic valve; LVEF, left ventricular ejection fraction; MR, mitral regurgitation.

of PPM insertion (OR: 1.01; 95\% CI: 0.99-1.03). When 219 individual valve leaflets were assessed, no significant 220 association was found (LCL: OR: 1.03, 95\% CI: 0.99-1.07; 221 NCL: OR: 1.02, 95\% CI: 0.98-1.06; RCL: OR: 1.01, 95\% 222 CI: 0.97-1.06). There was no identified association between 223 the presence of LVOT calcification and risk of PPI (OR: 224 0.86; 95\% CI: 0.38-1.93). 225

We analysed differences in PR interval in patients with 226 sinus rhythm before and after the TAVI: in 146 patients 227 with recorded pre- and post-procedure PR intervals. 228 The mean increase in PR interval duration after TAVI 229 in patients with below median NCL calcium scores was 230 $5.1 \pm 23.8$ compared to $12.3 \pm 32.1 \mathrm{~ms}(\mathrm{P}=0.13)$ with above 231 median calcium scores. A similar difference in PR interval 232 elongation was found with below $v s$. above median LCL 233 calcium scores $(6.2 \pm 26.3$ vs. $11.3 \pm 30.2 \mathrm{~ms}, \mathrm{P}=0.28)$, while 234 there was minimal difference when assessing RCL scores 235 (Figure $5 A, B, C$ ), There were no differences in the degree of 236 QRS duration elongation after TAVI in patients with above 237 or below median calcium scores in each individual valve 238 leaflet (Figure $5 D, E, F)(\mathrm{RCL} \mathrm{P}=0.40, \mathrm{LCL} \mathrm{P}=0.41$, and 239 NCL $\mathrm{P}=0.99) \quad 240$

242

243

Our study aimed to demonstrate the feasibility of individual 244 

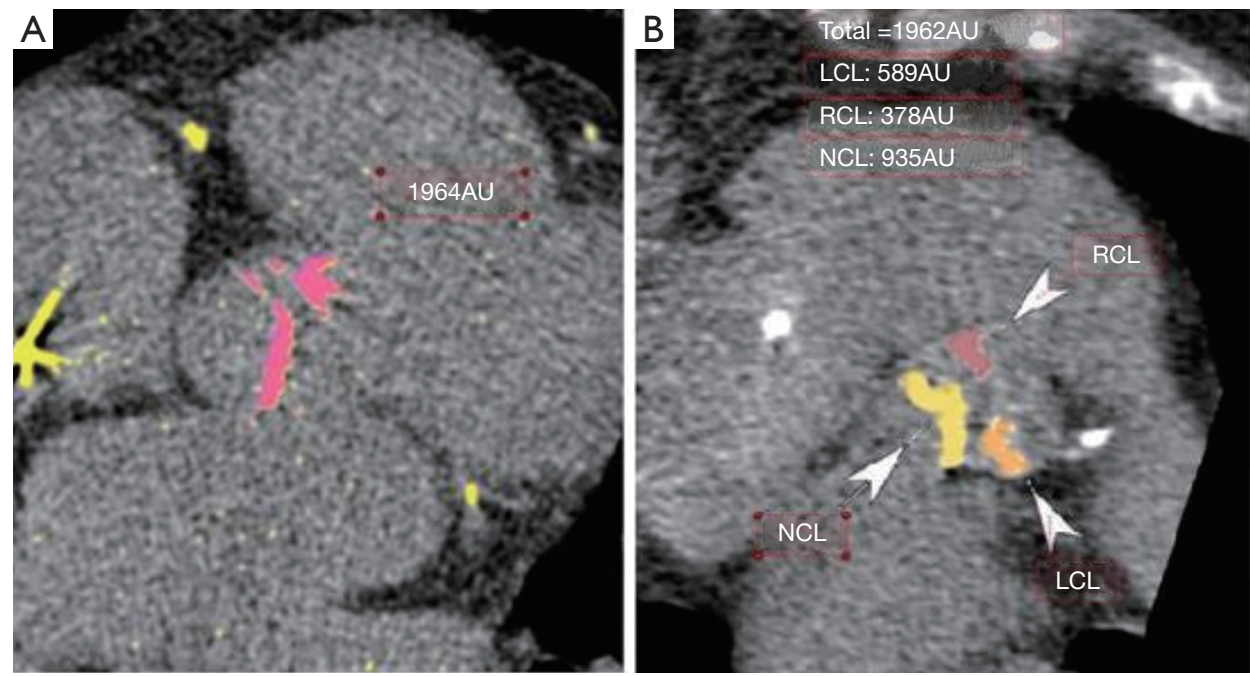

Figure 2 Aortic valve and individual aortic valve leaflet calcification scores. (A) Aortic valve calcium score trans-axial view; and (B) aortic valve calcium score en-face view. LCL, left coronary leaflet; NCL, non-coronary leaflet; RCL, right coronary leaflet; AU, Agatston unit.

aortic leaflet calcification measurement and to investigate its association between PVR and PPI in a contemporary cohort of patients treated with the Evolut $\mathrm{R}^{\mathrm{TM}}$ valve system.

Firstly, we have demonstrated that measurement of individual aortic valve calcium scores is feasible using the short axial stack, previous studies have looked at the transaxial view that is utilized. It demonstrated close agreement to the score obtained when measuring total valve calcium score with the Agatston method. This adds to the growing data on measurement of aortic valve calcium, which has already shown high levels of agreement between pre-surgery CT aortic valve calcium scores and $e x$-vivo calcium content using the volume scoring system (20). Commercially available software platforms (GE, Philips, Siemens, 3 mensio) have also shown strong levels of agreement with comparable results for calcium scoring using the volume score (19). Terarecon was not included in this analysis and we believe this is the first study to demonstrate that Terarecon can be used for quantifying aortic valve calcium with good agreement between individual calcium leaflet scores and the total calcium score using the Agatston method.

Secondly, we looked at the consequences of calcification on PVR. It is well accepted that the presence of extensive calcification in the landing zone precludes complete prosthesis expansion and its precise apposition to the native valve and LVOT (17,21-26). Delgado et al. was one of the first groups that used multi-detector computer tomography
(MDCT) to demonstrate an association between the degree of calcification and PVR in TAVI patients (26). More recently attention has focused on the effects of individual aortic leaflet and LVOT calcification. Significant calcification of the NCL has been associated with significant PVR using the first generation self-expanding Medtronic Corevalve ${ }^{\mathrm{TM}}$ (16). Conversely, our experience with the second-generation Medtronic Corevalve Evolut $\mathrm{R}^{\mathrm{TM}}$ demonstrated that RCL and LCL calcification was more strongly associated with PVR than NCL calcification, even after adjustment for elliptical annulus and valve sizing relative to the CT derived perimeter measurement. This is likely secondary to differences in frame design between the devices. Compared with the Corevalve ${ }^{\mathrm{TM}}$ device, the Evolut $\mathrm{R}^{\mathrm{TM}}$ device frame design provides more consistent radial force across the annular range, and the sealing skirt. Sealing skirts have been shown to lower the rates of PVR (27). The newer Medtronic devices also have ability to recapture and reposition the device $(5,28)$, which allows operators to achieve optimal valve position and to minimise PVR. Although multivariate analysis was performed, it is difficult to determine which if any of these features may contribute to changes in PVR severity and position. Moreover, perhaps the explanation is similar in that asymmetry of the aortic valve calcium. In this study a difference of $100 \mathrm{HU}$ between the RCL or LCL and the NCL predisposed to PVR. Of note the Acurate neo valve ${ }^{\mathrm{TM}}$ (Boston Scientific) has also developed their own new frame design to offer more 

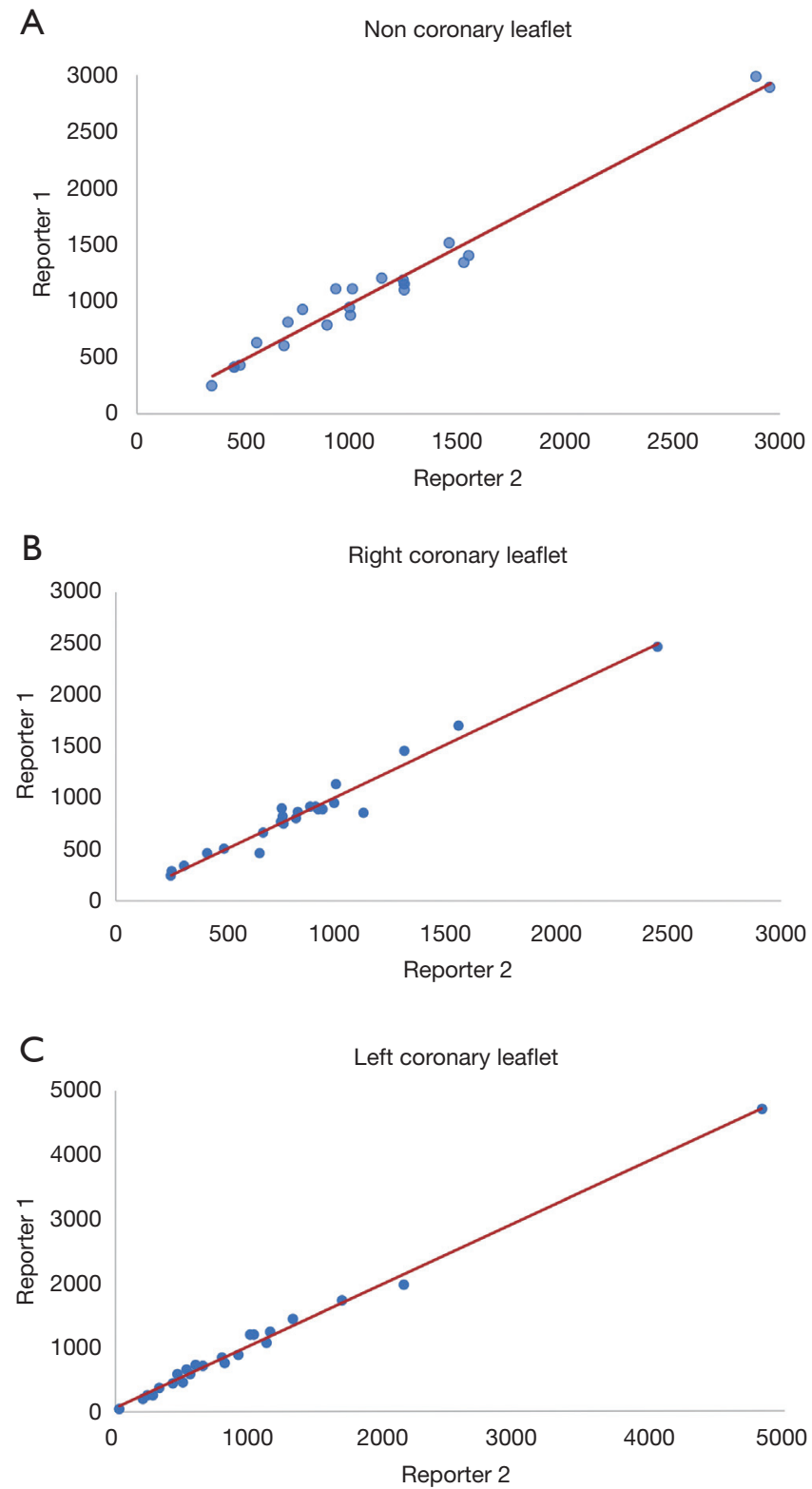

Figure 3 Intra-observer variability. (A-C) Scatter plots with line of best fit and spearman correlation coefficients for measured individual aortic valve leaflet scores between two independent blinded reporting doctors. consistent radial force. However, the SCOPE I trial showed that TAVI with the self-expanding Acurate neo valve ${ }^{\mathrm{TM}} \mathrm{did}$ not meet criteria for non-inferiority compared with balloonexpandable Sapien $3^{\mathrm{TM}}$ valve among patients undergoing trans-femoral TAVI with respect to PVR (29). The Sapien $3^{\mathrm{TM}}$ device has a novel flared inflow morphology which
A

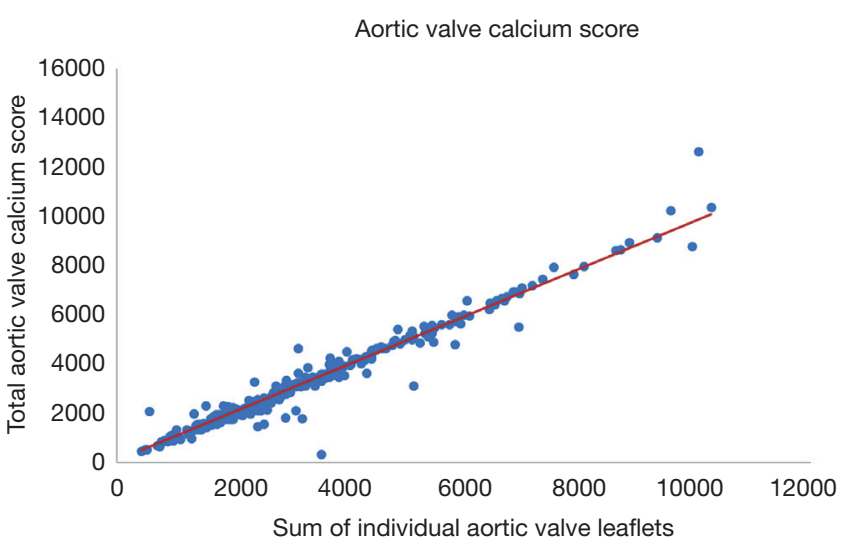

B Aortic valve calcium score

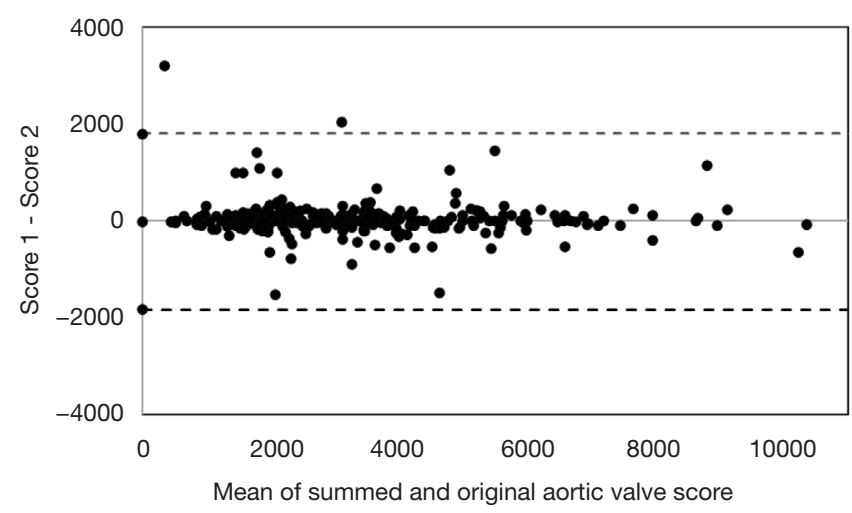

Figure 4 The relationship between total aortic valve calcification and the sum of individual aortic leaflet calcification. (A) Scatter plot comparing routinely measured aortic valve calcium score with the sum of the scores of each individual aortic valve leaflet; (B) Bland-Altman plot demonstrating no evidence of systematic bias between each measurement method.

may also contribute to a lesser degree of PVR with new generation devices (30).

Thirdly, we found no significant association between individual calcium leaflet burden and risk of PPI. Further, there was no identified association between the presence of LVOT calcification and risk of PPI. The PPI rate post CoreValve Evolut $\mathrm{R}^{\mathrm{TM}}$ prosthesis has been evaluated in numerous studies and varies from $14.7 \%$ (31) to $26.7 \%$ (3). Previously, identified risk factors for PPI, primarily with self-expanding design, include RBBB, low device implantation, conduction system abnormalities, and ratio of bioprosthesis diameter to LVOT diameter $(29,31,32)$. A lack of association seen in this study may again be 
Table 2 Individual aortic valve leaflet Agatston scores

\begin{tabular}{lccc}
\hline Variables & Calcium score $(\mathrm{AU})$ & Indexed for BSA $\left(\mathrm{AU} / \mathrm{m}^{2}\right)$ & Indexed for perimeter $(\mathrm{AU} / \mathrm{cm})$ \\
\hline LCL calcium score & $1,119 \pm 768$ & $637 \pm 436$ & $14.47 \pm 9.5$ \\
RCL calcium score & $953 \pm 644$ & $541 \pm 371$ & $12.31 \pm 7.8$ \\
NCL calcium score & $1,210 \pm 727$ & $696 \pm 417$ & $15.71 \pm 8.68$ \\
Total & $3,278 \pm 1,844$ & $1,872 \pm 1,054$ & $41.91 \pm 22.56$ \\
AV calcium score & $3,244 \pm 1,896$ & $1,855 \pm 1,088$ & $42.44 \pm 22.01$ \\
\hline
\end{tabular}

Agatston scores indexed for BSA; and Agatston scores indexed for CT derived perimeter measurements. BSA, body surface area; CT, computed tomography; $\mathrm{AU}$, Agatston unit; LCL, left coronary leaflet; RCL, right coronary leaflet; NCL, non-coronary leaflet; AV, aortic valve.

Table 3 Association between aortic valve leaflet calcium score (per 100 AU increase) and paravalvular leak on univariate analysis; and adjusted for valve under sizing and annulus eccentricity

\begin{tabular}{|c|c|c|c|c|}
\hline \multirow[t]{2}{*}{ Variables } & \multicolumn{2}{|c|}{ Univariate analysis } & \multicolumn{2}{|c|}{$\begin{array}{l}\text { Adjusted for valve under sizing and annulus } \\
\text { eccentricity }\end{array}$} \\
\hline & OR $(95 \% \mathrm{Cl})$ & $P$ value & OR $(95 \% \mathrm{Cl})$ & $P$ value \\
\hline NCL calcium score (per $100 \mathrm{AU}$ increase) & $1.04(0.98-1.09)$ & 0.18 & $1.03(0.98-1.08)$ & 0.305 \\
\hline LCL calcium score (per $100 \mathrm{AU}$ increase) & $1.06(1.01-1.11)$ & 0.02 & $1.05(1-1.1)$ & 0.047 \\
\hline
\end{tabular}

$\mathrm{OR}$, odds ratio; $\mathrm{Cl}$, confidence interval; $\mathrm{AU}$, Agatston unit; NCL, non-coronary leaflet; LCL, left coronary leaflet; RCL, right coronary leaflet; $\mathrm{AV}$, aortic valve.

Table 4 Association between aortic valve leaflet calcium score (per 100 AU increase) and requirement for post-TAVI balloon valvuloplasty; and adjusted for valve under sizing and annulus eccentricity

\begin{tabular}{|c|c|c|c|c|}
\hline \multirow{2}{*}{ Variables } & \multicolumn{2}{|c|}{ Univariate analysis } & \multicolumn{2}{|c|}{$\begin{array}{l}\text { Adjusted for valve under sizing and annulus } \\
\text { eccentricity }\end{array}$} \\
\hline & OR $(95 \% \mathrm{Cl})$ & $P$ value & OR $(95 \% \mathrm{Cl})$ & $P$ value \\
\hline LCL calcium score (per $100 \mathrm{AU}$ increase) & $1.07(1.03-1.11)$ & $<0.001$ & $1.07(1.03-1.11)$ & 0.001 \\
\hline
\end{tabular}

explained in part by the frame design. The aortic valve is in close anatomical proximity to the AV node and left bundle branch (33). Applying consistent radial force across the annular range, rather than a focus in the annulus, such as near the AV node. Data from CT scans performed in patients treated with the SAPIEN $3^{\mathrm{TM}}$ showed that the amount of calcification in the device landing zone was independently associated with post-TAVI PPI (16,26,34). 328 Direct mechanical trauma or compression of the AV node 329 or the left bundle branch by balloon dilation or prosthesis 330 implantation can cause a high-degree AV block or left 331 bundle BBB during or after TAVI (35). Our findings are 332 consistent with previous studies that the second-generation 333 Medtronic Corevalve Evolut $\mathrm{R}^{\mathrm{TM}}$ rates of PPI are 23\%. 334 
A

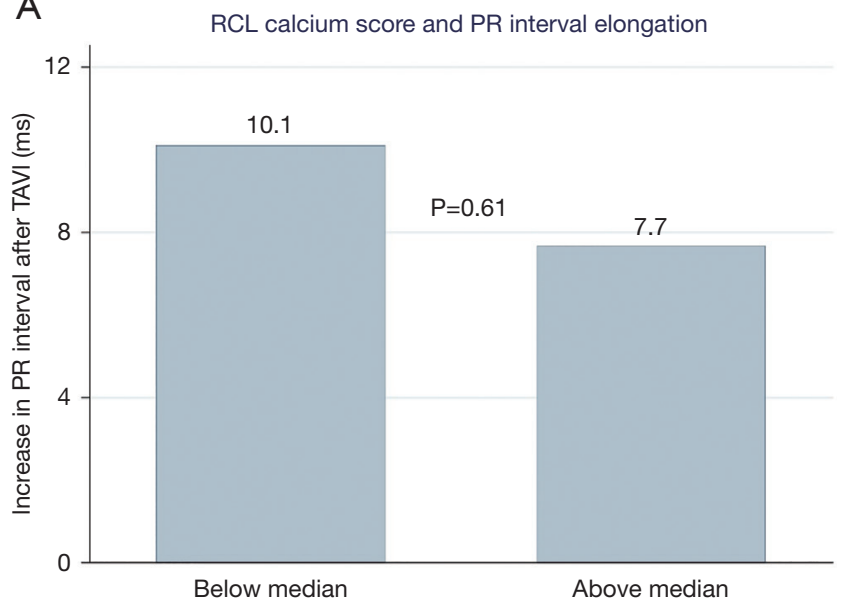

C

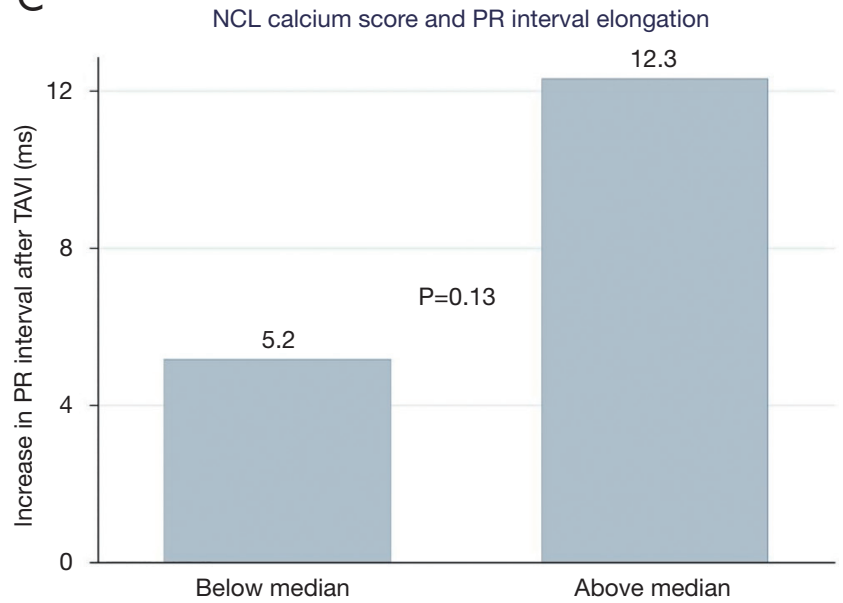

E

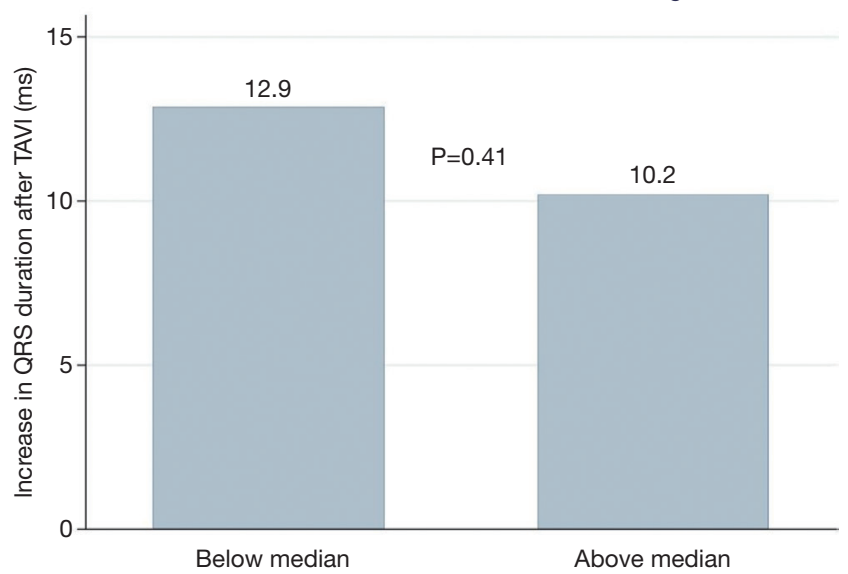

B

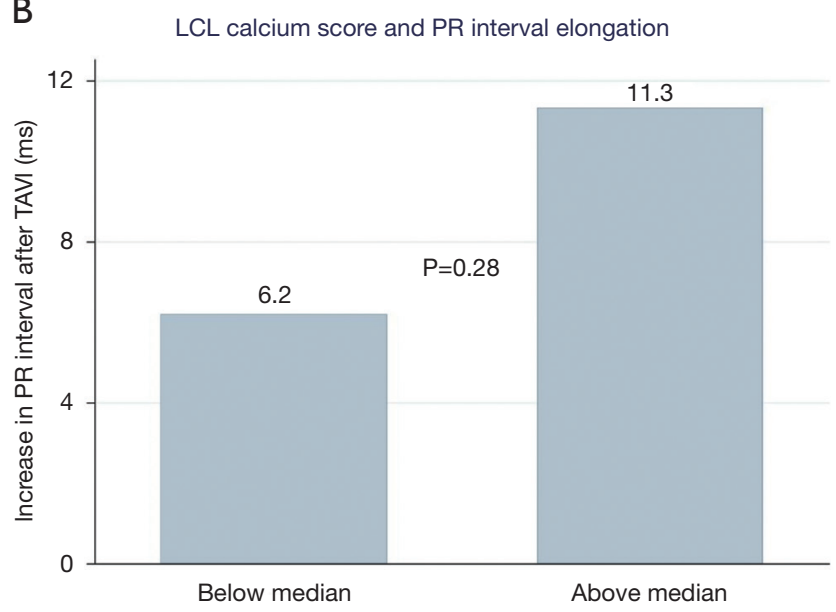

D

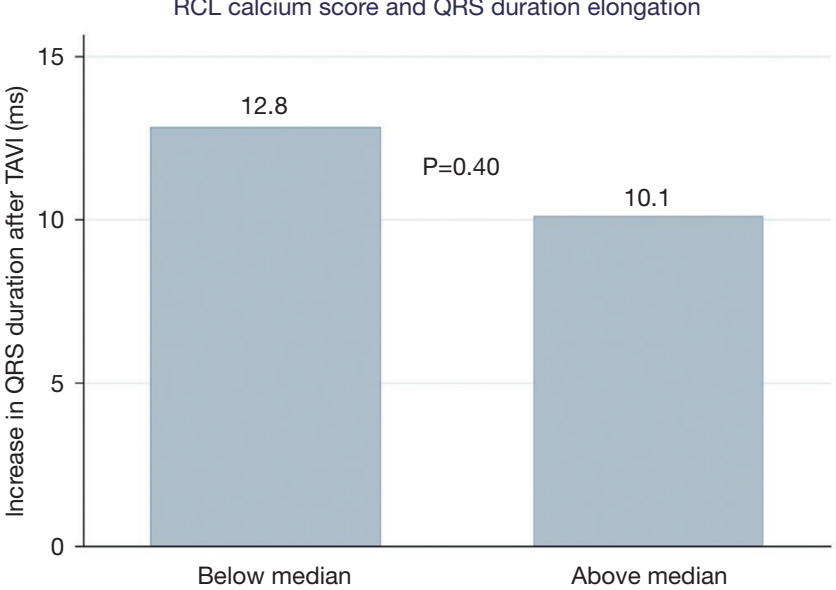

$\mathrm{F}$

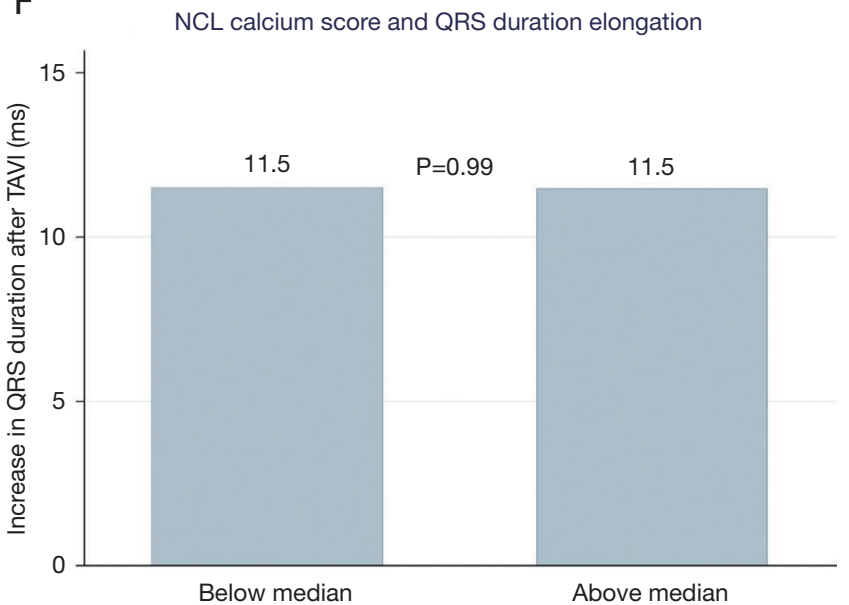

Figure 5 Column charts demonstrating (A-C) the increase in PR interval post TAVI in the RCL, LCL and NCL respectively above and below the median; (D-F) the increase in QRS interval post TAVI the RCL, LCL and NCL respectively above and below the median. TAVI, trans-catheter aortic valve implantation; LCL, left coronary leaflet; NCL, non-coronary leaflet; RCL, right coronary leaflet. 
However, there was no predisposition to spatial distribution of calcium on PPI rates. Aortic valve calcium score appeared to have a larger effect on PR interval compared to QRS interval although this was not statistically significant. Further, it should be noted that the bundle of His and branches sit below the valve annulus so the displacement of the valve leaflets into the sinuses may not necessarily cause conduction problems. This would also explain why little association was found between valve leaflet calcium scores and lengthening of QRS duration.

Finally, the anatomical proximity to the conduction system of LVOT calcification may play an important determinant for risk of conduction abnormalities and pacing too. Indeed, the Lotus valve showed an independent association between the LVOT calcification as assessed with CT and increased risk of post-TAVI PPI (36). However, there was no identified association between the presence of LVOT calcification and risk of PPI in our study.

One limitation of this study is our use of the Agatston scoring method over the volume method. The specification for calcium scoring were developed for electron beam CT scanners and have since been adapted to modern dual source scanners and MDCT scanners (37). The Agatston scoring system gives a maximum CT attenuation to each lesion. A weight of 1 is given for attenuation of 130 to 199; 2 for 200 to 299; 3 for 300 to 399; and 4 for attenuation $\geq 400$ (18). In contrast, the volume score does not apply a density weighting. It simply measures the volume of calcium (pixels with $\mathrm{HU}>130$ ). We chose the Agatston score as it is the standard technique for the evaluation of aortic valve severity. There is reported improved interscan reproducibility with the volume method compared to the Agatston method, although any differences are modest (38). With a relatively large slice thickness ( $3 \mathrm{~mm}$ on MDCT) small and low-density calcifications may not reach the $130 \mathrm{HU}$ threshold due to partial volume effect, however, given the high burden of calcium in severe aortic stenosis this would not significantly affect our result. Further, the reproducibility of calcium score does decrease with large slice thickness, however, this is likely more significant in small calcification deposits, in particular in the coronary calcium setting. That is to say the larger the calcium burden, it is anticipated that there would be a smaller standard error. The high degree of correlation with interobserver measurements would support this. Further recent advances in iterative reconstruction have improved signal to noise in the processed image, potentially also allowing for increased calcium-score accuracy $(39,40)$ with the Agatston method.

382

\section{Conclusions}

Individual aortic valve leaflet calcium quantification is feasible using the short axis view on Terarecon software platform, and correlates well with the total calcium score. Asymmetry in the severely calcified aortic valve at the RCL and LCL as determined by aortic leaflet calcification difference of $100 \mathrm{HU}$ was associated with an increased risk of PVR with the Medtronic Evolut $\mathrm{R}^{\mathrm{TM}}$ valve system. This supports the idea that a quantifiable and reproducible method of individual valve leaflet calcification score may serve as an independent risk factor for PVR, beyond visual assessment of asymmetry. However, the same may not be true of spatial calcium distribution and PPI.

\section{Acknowledgments}

This manuscript has not been previously published or submitted for publication elsewhere except as a brief abstract in the proceedings of a scientific meeting or symposium. The abstract of our manuscript was submitted to the 2020 JCCT 15th Annual Scientific Meeting and was accepted as an oral presentation. All accepted original science presentations have been published in the July issue of Journal of Cardiovascular Computer Tomography, 2020. Funding: None.

\section{Footnote}

Conflicts of Interest: All authors have completed the ICMJE uniform disclosure form (available at http://dx.doi. org/10.21037/qims-20-1122). The authors have no conflicts of interest to declare.

Ethical Statement: The study was approved by institutional ethics board of Royal Brompton and Harefield Trust and individual consent for this retrospective analysis was waived.

Open Access Statement: This is an Open Access article distributed in accordance with the Creative Commons Attribution-NonCommercial-NoDerivs 4.0 International License (CC BY-NC-ND 4.0), which permits the noncommercial replication and distribution of the article with the strict proviso that no changes or edits are made and the 
original work is properly cited (including links to both the formal publication through the relevant DOI and the license). See: https://creativecommons.org/licenses/by-nc-nd/4.0/.

\section{References}

1. Ussia GP, Barbanti M, Petronio AS, Tarantini G, Ettori F, Colombo A, Violini R, Ramondo A, Santoro G, Klugmann S, Bedogni F, Maisano F, Marzocchi A, Poli A, De Carlo M, Napodano M, Fiorina C, De Marco F, Antoniucci D, de Cillis E, Capodanno D, Tamburino C; CoreValve Italian Registry Investigators. Transcatheter aortic valve implantation: 3 -year outcomes of self-expanding CoreValve prosthesis. Eur Heart J 2012;33:969-76.

2. Leon MB, Smith CR, Mack MJ, Makkar RR, Svensson LG, Kodali SK, Thourani VH, Tuzcu EM, Miller DC, Herrmann HC, Doshi D, Cohen DJ, Pichard AD, Kapadia S, Dewey T, Babaliaros V, Szeto WY, Williams MR, Kereiakes D, Zajarias A, Greason KL, Whisenant BK, Hodson RW, Moses JW, Trento A, Brown DL, Fearon WF, Pibarot P, Hahn RT, Jaber WA, Anderson WN, Alu MC, Webb JG; PARTNER 2 Investigators. Transcatheter or surgical aortic-valve replacement in intermediate-risk patients. N Engl J Med 2016;374:1609-20.

3. Reardon MJ, Van Mieghem NM, Popma JJ, Kleiman NS, Søndergaard L, Mumtaz M, Adams DH, Deeb GM, Maini B, Gada H, Chetcuti S, Gleason T, Heiser J, Lange R, Merhi W, Oh JK, Olsen PS, Piazza N, Williams M, Windecker S, Yakubov SJ, Grube E, Makkar R, Lee JS, Conte J, Vang E, Nguyen H, Chang Y, Mugglin AS, Serruys PW, Kappetein AP; SURTAVI Investigators. Surgical or transcatheter aortic-valve replacement in intermediate-risk patients. N Engl J Med 2017;376:1321-31.

4. Herrmann HC, Thourani VH, Kodali SK, Makkar RR, Szeto WY, Anwaruddin S, Desai N, Lim S, Malaisrie SC, Kereiakes DJ, Ramee S, Greason KL, Kapadia S, Babaliaros V, Hahn RT, Pibarot P, Weissman NJ, Leipsic J, Whisenant BK, Webb JG, Mack MJ, Leon MB; PARTNER Investigators. One-year clinical outcomes with SAPIEN 3 transcatheter aortic valve replacement in highrisk and inoperable patients with severe aortic stenosis. Circulation 2016;134:130-40.

5. Popma JJ, Reardon MJ, Khabbaz K, Harrison JK, Hughes GC, Kodali S, George I, Deeb GM, Chetcuti S, Kipperman R, Brown J, Qiao H, Slater J, Williams M. Early clinical outcomes after transcatheter aortic valve replacement using a novel self-expanding bioprosthesis in patients with severe aortic stenosis who are suboptimal for surgery: results of the Evolut R U.S. study. JACC Cardiovasc Interv 2017;10:268-75.

6. Généreux P, Head SJ, Wood DA, Kodali SK, Williams MR, Paradis JM, Spaziano M, Kappetein AP, Webb JG, Cribier A, Leon MB. Transcatheter aortic valve implantation: 10-year anniversary. Part II: clinical implications. Eur Heart J 2012;33:2399-402.

7. Tamburino C, Capodanno D, Ramondo A, Petronio AS, Ettori F, Santoro G, Klugmann S, Bedogni F, Maisano F, Marzocchi A, Poli A, Antoniucci D, Napodano M, De Carlo M, Fiorina C, Ussia GP. Incidence and predictors of early and late mortality after transcatheter aortic valve implantation in 663 patients with severe aortic stenosis. Circulation 2011;123:299-308.

8. De Jaegere PP, Piazza N, Galema TW, Otten A, Soliman OI, Van Dalen BM, Geleijnse ML, Kappetein AP, Garcia HM, Van Es GA, Serruys PW. Early echocardiographic evaluation following percutaneous implantation with the self-expanding CoreValve Revalving System aortic valve bioprosthesis. EuroIntervention 2008;4:351-7.

9. Abdel-Wahab M, Zahn R, Horack M, Gerckens U, Schuler G, Sievert H, Eggebrechy H, Senges J, Richart G. Aortic regurgitation after transcatheter aortic valve implantation: incidence and early outcome. Results from the German transcatheter aortic valve interventions registry. Heart 2011;97:899-906.

10. Sinning JM, Hammerstingl C, Vasa-Nicotera M, Adenauer V, Cachiguango SJL, Scheer AC, Hausen S, Sedaghat A, Ghanem A, Muller C,Grube E, Nickenig G, Nikos $W$. Aortic regurgitation index defines severity of periprosthetic regurgitation and predicts outcome in patients after transcatheter aortic valve implantation. J Am Coll Cardiol 2012;59:1134-41.

11. Hansson NC, Leipsic J, Pugliese F, Andersen HR, Rossi A, Simonato M, Jensen KT, Christiansen EH, Terkelsen CJ, Blanke P, Tang M, Krussell LR, Klaaborg KE, Terp K, Kennon S, Dvir D, Botker HE, Webb, Norgaard BL. Aortic valve and left ventricular outflow tract calcium volume and distribution in transcatheter aortic valve replacement: Influence on the risk of significant paravalvular regurgitation. J Cardiovasc Comput Tomogr 2018;12:290-7.

12. Buellesfeld L, Stortecky S, Heg D, Gloekler S, Meier B, Wenaweser P, Windecker S. Extent and distribution of calcification of both the aortic annulus and the left 
ventricular outflow tract predict aortic regurgitation after transcatheter aortic valve replacement. EuroIntervention 2014;10:732-8.

13. Kodali SK, Williams MR, Smith CR, Svensson LG, Webb JG, Makkar RR, Fontana GP, Dewey TM, Thourani VH, Pichard AD, Fischbein M, Szeto WY, Lim S, Greason KL, Teirstein PS, Malaisrie SC, Douglas PS, Hahn RT, Whisenant B, Zajarias A, Wang D, Akin JJ, Anderson WN, Leon MB; PARTNER Trial Investigators. Twoyear outcomes after transcatheter or surgical aortic-valve replacement. N Engl J Med 2012;366:1686-95.

14. Athappan G, Patvardhan E, Tuzcu EM, Svensson LG, Lemos PA, Fraccaro C, Tarantini G, Sinning JM, Nickenig G, Capodanno D, Tamburino C, Latib A, Colombo A, Kapadia S. Incidence, predictors, and outcomes of aortic regurgitation after transcatheter aortic valve replacement: meta-analysis and systematic review of literature. J Am Coll Cardiol 2013;61:1585-95.

15. Hayashida K, Lefèvre T, Chevalier B, Hovasse T, Romano M, Garot P, Bouvier E, Farge A, Donzeau-Gouge P, Cormier B, Morice MC. Impact of post-procedural aortic regurgitation on mortality after transcatheter aortic valve implantation. JACC Cardiovasc Interv 2012;5:1247-56.

16. Maeno Y, Abramowitz Y, Kawamori H, Kazuno Y, Kubo S, Takahashi N, Mangat G, Okuyama K, Kashif M, Chakravarty T, Nakamura M, Cheng W, Friedman, Berman D, Makkar RR, Jilaihawi H. A highly predictive risk model for pacemaker implantation after TAVR. JACC Cardiovasc Imaging 2017;10:1139-47.

17. Terré JA, George I, Smith CR. Pros and cons of transcatheter aortic valve implantation (TAVI). Ann Cardiothorac Surg 2017;6:444-52.

18. Pawade T, Sheth T, Guzzetti E, Dweck MR, Clavel MA. Why and how to measure aortic valve calcification in patients with aortic stenosis. JACC Cardiovasc Imaging 2019;12:1835-48.

19. Gorla R, Marco F De, Morganti S, Finotello A, Brambilla N, Testa L, Agnifili ML, Tusa M, Auricchio F, Bedogni F. Transcatheter aortic valve implantation with Portico and Evolut-R in patients with elliptic aortic annulus. EuroIntervention 2020;15:e1588-91.

20. Messika-Zeitoun D, Aubry MC, Detaint D, Bielak LF, Peyser PA, Sheedy PF, Turner ST, Breen JF, Scott C, Tajik AJ, Enriquez-Sarano M. Evaluation and clinical implications of aortic valve calcification measured by electron-beam computed tomography. Circulation 2004;110:356-62.

21. Haensig M, Lehmkuhl L, Rastan AJ, Kempfert J,
Mukherjee C, Gutberlet M, Holzhey DM, Mohr FW. Aortic valve calcium scoring is a predictor of significant paravalvular aortic insufficiency in transapical-aortic valve implantation. Eur J Cardiothorac Surg 2012;41:1234-40; discussion 1240-1.

22. Détaint D, Lepage L, Himbert D, Brochet E, MessikaZeitoun D, Iung B, Vahanian A. Determinants of significant paravalvular regurgitation after transcatheter aortic valve implantation: impact of device and annulus discongruence. JACC Cardiovasc Interv 2009;2:821-7.

23. Yoon SH, Ahn JM, Ohno Y, Barbanti M, Chan J, Lin MS, Kim YH, Yang DH, Sugiyama D, Chan KT, Immé S, Tamburino CI, Sgroi C, Park DW, Kang SJ, Lee SW, Lee CW, Park SW, Lee M, Kao HL, Tamburino C, Park SJ. Predictors for paravalvular regurgitation after TAVR with the self-expanding prosthesis: quantitative measurement of MDCT analysis. JACC Cardiovasc Imaging 2016;9:1233-4.

24. Almeida JG, Ferreira SM, Fonseca P, Dias T, Guerreiro C, Barbosa A, Teixeira P, Carvalho M, Ferreira W, Ferreira ND, Braga P, Ribeiro J, Ribeiro VG. Comparison of selfexpanding and balloon-expandable transcatheter aortic valves morphology and association with paravalvular regurgitation: Evaluation using multidetector computed tomography. Catheter Cardiovasc Interv 2018;92:533-41.

25. Kim WK, Blumenstein J, Liebetrau C, Rolf A, Gaede L, Van Linden A, Arsalan M, Doss M, Tijssen JGP, HammCW, Walther T, Mollmann H. Comparison of outcomes using balloon-expandable versus self-expanding transcatheter prostheses according to the extent of aortic valve calcification. Clin Res Cardiol 2017;106:995-1004.

26. Delgado V, Ng ACT, Van De Veire NR, Van Der Kley F, Schuijf JD, Tops LF, De Weger A, Tavilla G, De Roos A, Kroft LJ, Schalij MJ, Bax JJ. Transcatheter aortic valve implantation: role of multi-detector row computed tomography to evaluate prosthesis positioning and deployment in relation to valve function. Eur Heart J 2010;31:1114-23.

27. Nomura T, Maeno Y, Yoon SH, Abramowitz Y, Israr S, Miyasaka M, Kazuno Y, Takahashi N, Kawamori H, Nakamura M, Jilaihawi H, Makkar RR. Early clinical outcomes of transcatheter aortic valve replacement in left ventricular outflow tract calcification: new-generation device vs early-generation device. J Invasive Cardiol 2018;30:421-7.

28. Sorajja P, Kodali S, Reardon MJ, Szeto WY, Chetcuti SJ, Hermiller J, Chenoweth S, Adams DH, Popma, JJ. Outcomes for the commercial use of self-expanding 
prostheses in transcatheter aortic valve replacement: a report from the STS/ACC TVT registry. JACC Cardiovasc Interv 2017;10:2090-8.

29. Lanz J, Kim WK, Walther T, Burgdorf C, Möllmann H, Linke A, Redwood S, Thilo C, Hilker M, Joner M, Thiele H, Conzelmann L, Conradi L, Kerber S, Schymik G, Prendergast B, Husser O, Stortecky S, Heg D, Jüni P, Windecker S, Pilgrim T; SCOPE I investigators. Safety and efficacy of a self-expanding versus a balloonexpandable bioprosthesis for transcatheter aortic valve replacement in patients with symptomatic severe aortic stenosis: a randomised non-inferiority trial. Lancet 2019;394:1619-28.

30. Kazuno Y, Maeno Y, Kawamori H, Takahashi N, Abramowitz Y, Babak H, Kashif M, Chakravarty, Nakamura M, Cheng W, Friedman J, Berman D, Makkar RR, Jilaihawai H. Comparison of SAPIEN 3 and SAPIEN $\mathrm{XT}$ transcatheter heart valve stent-frame expansion: evaluation using multi-slice computed tomography. Eur Hear J Cardiovasc Imaging 2016;17:1054-62.

31. Kalra SS, Firoozi S, Yeh J, Blackman DJ, Rashid S, Davies S, Moat N, Dalby M, Kabir T, Khogali SS, Anderson RA, Groves PH, Mylotte D, Hildick-Smith D, Rampat R, Kovac J, Gunarathne A, Laborde JC, Brecker SJ. Initial experience of a second-generation selfexpanding transcatheter aortic valve: the UK \& Ireland Evolut R implanters' registry. JACC Cardiovasc Interv 2017;10:276-82.

32. Erkapic D, De Rosa S, Kelava A, Lehmann R, Fichtlscherer S, Hohnloser SH. Risk for permanent pacemaker after transcatheter aortic valve implantation: a comprehensive analysis of the literature. J Cardiovasc Electrophysiol 2012;23:391-7.

33. Gomes B, Geis NA, Chorianopoulos E, Meder B, Leuschner F, Katus HA, Bekeredjian R. Improvements of procedural results with a new-generation self-expanding transfemoral aortic valve prosthesis in comparison to the old-generation device. J Interv Cardiol 2017;30:72-8.

34. Mauri V, Reimann A, Stern D, Scherner M, Kuhn E,
Rudolph V, Rosenkranz S, Eghbalzadeh K, Friedrichs K, Wahlers T, Baldus S, Madershahian N, Rudolph TK. Predictors of permanent pacemaker implantation after transcatheter aortic valve replacement with the SAPIEN 3. JACC Cardiovasc Interv 2016;9:2200-9.

35. Siontis GCM, Jüni P, Pilgrim T, Stortecky S, Büllesfeld L, Meier B, Wenaweser P, Windecker S. Predictors of permanent pacemaker implantation in patients with severe aortic stenosis undergoing TAVR: a meta-analysis. J Am Coll Cardiol 2014;64:129-40.

36. Dumonteil N, Meredith IT, Blackman DJ, Tchétché D, Hildick-Smith D, Spence MS, Walters DL, Harnek J, Worthley SG, Rioufol G, Lefevre T, Modine T, Van Mieghem N, Houle Vm, Allocco Dj, Dawkins KD. Insights into the need for permanent pacemaker following implantation of the repositionable LOTUS valve for transcatheter aortic valve replacement in 250 patients: results from the REPRISE II trial with extended cohort. EuroIntervention 2017;13:796-803.

37. Blaha MJ, Mortensen MB, Kianoush S, Tota-Maharaj R, Cainzos-Achirica M. Coronary artery calcium scoring: is it time for a change in methodology? JACC Cardiovasc Imaging 2017;10:923-37.

38. Alluri K, Joshi PH, Henry TS, Blumenthal RS, Nasir $\mathrm{K}$, Blaha MJ. Scoring of coronary artery calcium scans: History, assumptions, current limitations, and future directions. Atherosclerosis 2015;239:109-17.

39. den Harder AM, Wolterink JM, Willemink MJ, Schilham AMR, de Jong PA, Budde RPJ, Nathoe HM, Išgum I, Leiner T. Submillisievert coronary calcium quantification using model-based iterative reconstruction: a withinpatient analysis. Eur J Radiol 2016;85:2152-9.

40. Choi AD, Leifer ES, Yu J, Shanbhag SM, Bronson K, Arai AE, Chen MY. Prospective evaluation of the influence of iterative reconstruction on the reproducibility of coronary calcium quantification in reduced radiation dose 320 detector row CT. J Cardiovasc Comput Tomogr 2016;10:359-63.

Cite this article as: Mahon C, Davies A, Gambaro A, Musella F, Costa AL, Panoulas V, Nicol E, Duncan A, Davies S, Mirsadraee S. Association of individual aortic leaflet calcification on paravalvular regurgitation and conduction abnormalities with self-expanding trans-catheter aortic valve insertion. Quant Imaging Med Surg 2021;11(5):1970-1982. doi: 10.21037/qims20-1122 